\title{
Comparison of protein-repellent behavior of linear versus dendrimer- structured surface-immobilized polymers
}

\section{- Supporting information}

Jutta Lehnfeld ${ }^{a}$, Martina Gruening ${ }^{\mathrm{b}}$, Matthias Kronseder ${ }^{\mathrm{c}}$, Rainer Mueller ${ }^{\mathrm{a}}$

a Institute of Physical and Theoretical Chemistry, University of Regensburg, Universitätsstraße 31, 93053

Regensburg, Germany

${ }^{\mathrm{b}}$ Department of Cell Biology, Rostock University Medical Center, Schillingallee 69, 18057 Rostock, Germany

c Department of Physics, University of Regensburg, Universitätsstraße 31, 93053 Regensburg, Germany

* Corresponding author: Institute of Physical and Theoretical Chemistry, Universitätsstr.31, 93053 Regensburg, Germany; E-mail address: rainer.mueller@chemie.uni-regensburg.de, Tel: $+49-941943-4521$ 


\section{Table of Contents}

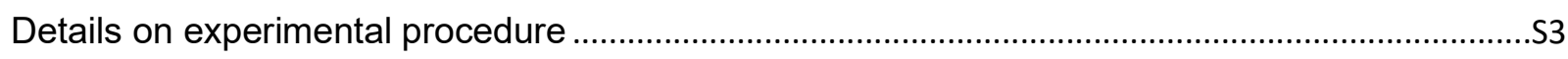

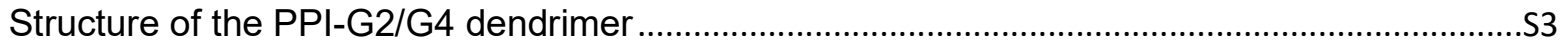

Reagent concentration for synthesis of APD, PPI-G2 and PPI-G4 modifications .......................S3

Surface tension components used for SFE calculation ...........................................................

Detailed description of experimental procedure for protein adsorption.......................................S4

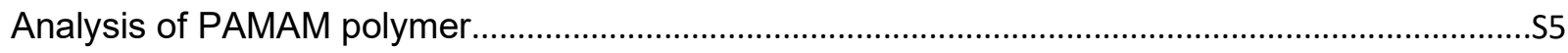

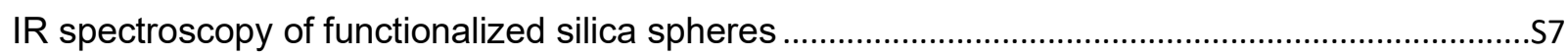

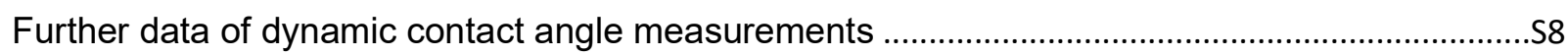

Dependence of protein adsorption on physicochemical surface properties ..................................S10

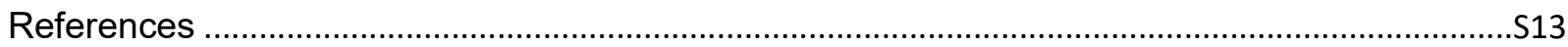




\section{Details on experimental procedure}

\section{Structure of the PPI-G2/G4 dendrimer}
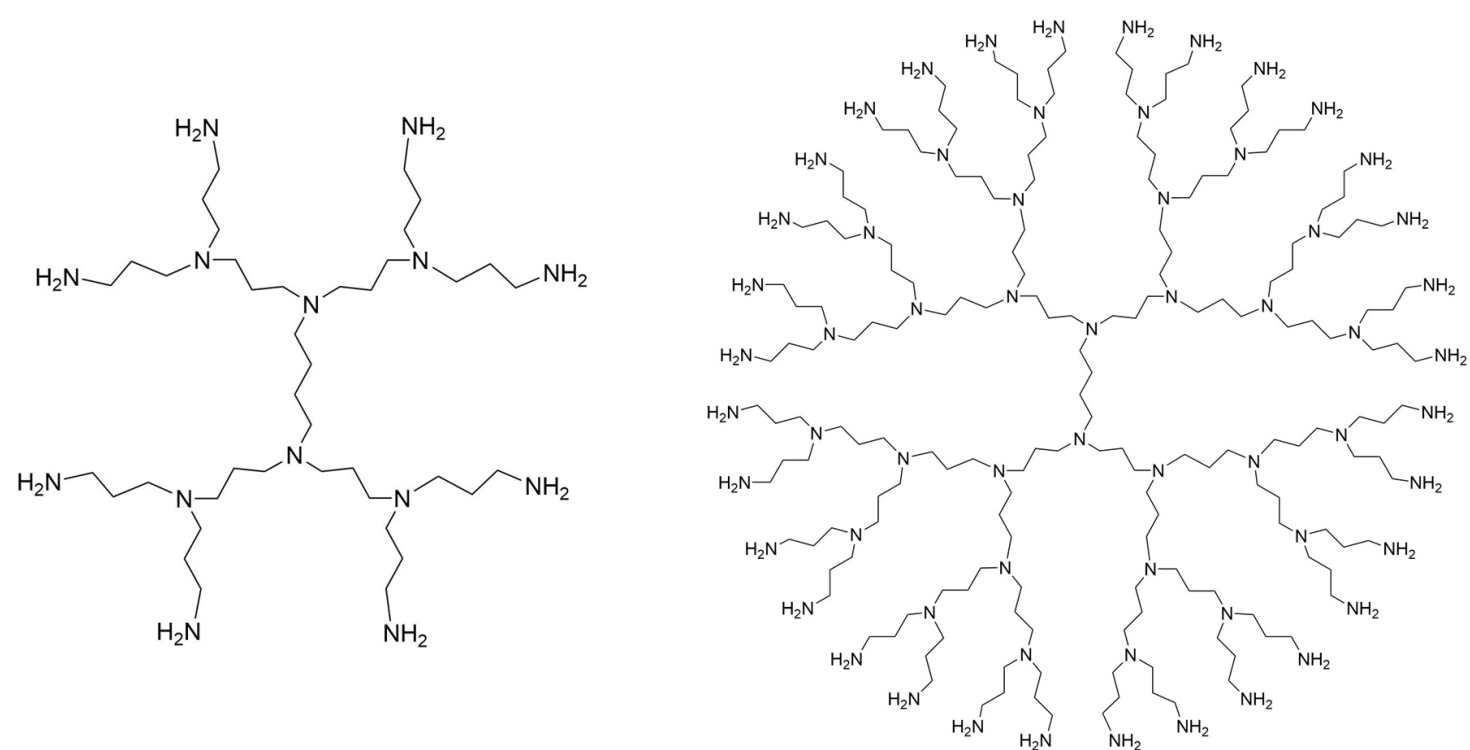

Figure S 1: Structure of the second generation (left) and fourth generation (right) poly(propylene imine) (PPI) dendrimer.

\section{Reagent concentration for synthesis of APD, PPI-G2 and PPI-G4 modifications}

Table S 1: Reagent concentration for the immobilization of APD, PPI-G2 and PPI-G4 on different substrates. Note that the concentrations decrease with increasing size of the molecules. For wafers $0.8 \mathrm{~mL}$ solution were used for $1 \mathrm{~cm}^{2}$ wafer, for silica beads $1.25 \mathrm{~mL}$ solution per gram beads were needed, for silica particles $5 \mathrm{~mL}$ solution per $100 \mathrm{mg}$ substrate were used.

\begin{tabular}{|c|c|c|c|}
\hline \multirow{2}{*}{$\begin{array}{l}\text { Reagent concentration } \\
{[\mathrm{mmol} / \mathrm{L}]}\end{array}$} & \multicolumn{3}{|c|}{ Substrate type } \\
\hline & Silicon wafer & Silica beads & Silica particles \\
\hline APD & 100 & 200 & 200 \\
\hline PPI-G2 & 5 & 50 & 10 \\
\hline PPI-G4 & 0.5 & 5 & 1 \\
\hline
\end{tabular}




\section{Surface tension components used for SFE calculation}

The surface tension components of water, formamide and diiodomethane which were used for the calculation of the SFE are summarized in the following table ${ }^{1}$ :

Table S 2: Surface tensions $y$ and their components (Lifshitz-van der Waals component $\gamma^{L W}$, Lewis acid component $\gamma^{+}$and Lewis base component $\gamma$ ) of water, formamide and diiodomethane for the calculation of the SFE of the surface modifications, as summarized by Kwok. ${ }^{1}$

\begin{tabular}{lcccc}
\hline & \multicolumn{4}{c}{ Surface tension (components) $[\mathrm{mN} / \mathrm{m}]$} \\
\cline { 2 - 5 } & $\mathrm{Y}$ & $\mathrm{Y}^{\mathrm{LW}}$ & $\mathrm{Y}^{+}$ & $\mathrm{Y}^{-}$ \\
\hline Water & 72.8 & 21.8 & 25.5 & 25.5 \\
\hline Formamide & 58 & 39 & 2.28 & 39.6 \\
\hline Diiodomethane & 50.8 & 50.8 & 0 & 0 \\
\hline
\end{tabular}

\section{Detailed description of experimental procedure for protein adsorption}

Protein adsorption was performed with undiluted physiological fluids (whole saliva and FBS) and single protein solutions (HSA and lysozyme, concentration $10 \mathrm{mg} / \mathrm{mL}$ ) in PBS puffer. To that purpose, $4 \mathrm{~mL}$ of protein solution were added per gram silica beads in polypropylene reaction cups by Eppendorf (Germany). Adsorption was performed for 60 min at $25{ }^{\circ} \mathrm{C}$ under constant agitation, achieved with an overhead shaker. Slightly attached proteins were removed via rinsing five times with PBS buffer and once with water ( $4 \mathrm{~mL}$ per gram beads each). Each rinsing step consisted of careful removal of the supernatant (protein) solution, addition of fresh buffer or water respectively and mixing of the suspension for five minutes with the overhead shaker. 


\section{Analysis of PAMAM polymer}

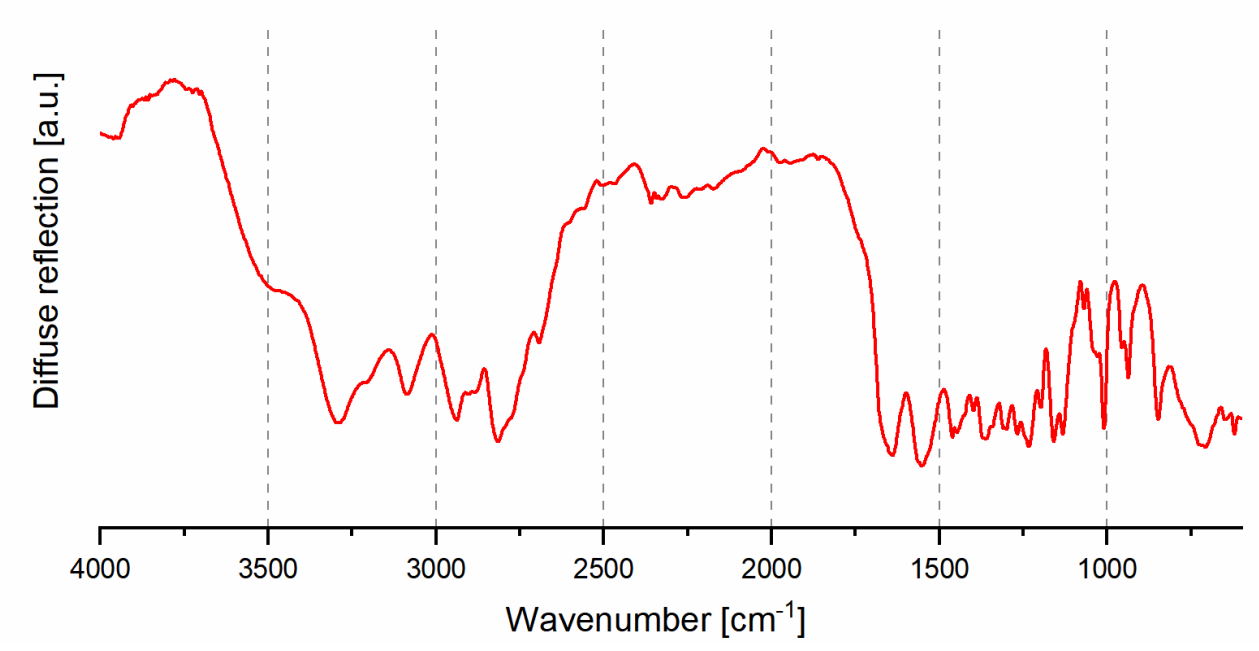

Figure S 2: DRIFT spectrum of PAMAM polymer. The following bands were assigned: $3294 \mathrm{~cm}^{-1}$ and $3087 \mathrm{~cm}^{-1}: v(\mathrm{~N}-H) ; 2937 \mathrm{~cm}^{-1}$ and $2815 \mathrm{~cm}^{-1}: v_{\text {as }}(\mathrm{C}-\mathrm{H})$ and $v_{s}(C-H) ; 1640 \mathrm{~cm}^{-1}:$ amide l, v(C=O); $1550 \mathrm{~cm}^{-1}$ : amide $I I, v(C-N)$ and $\delta(N-H)$.

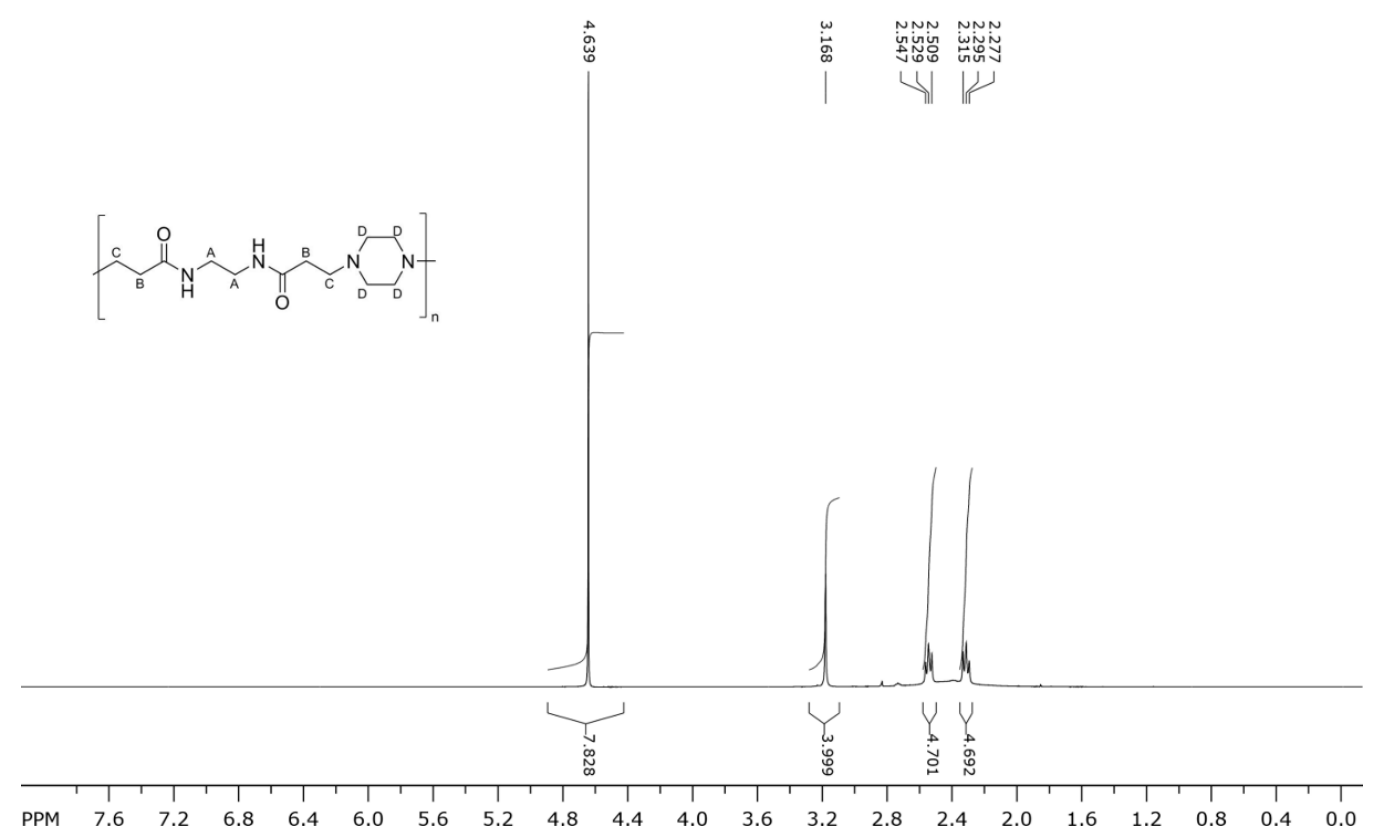

Figure $S 3:{ }^{1} \mathrm{H}-\mathrm{NMR}$ spectrum of the PAMAM polymer in $\mathrm{D}_{2} \mathrm{O}: \delta=2.295 \mathrm{ppm}\left(\mathrm{t}, \mathrm{J}=7.6 \mathrm{~Hz}, 4 \mathrm{H}_{B}\right), \delta=$ $2.529 \mathrm{ppm}\left(\mathrm{t}, \mathrm{J}=7.6 \mathrm{~Hz}, 4 \mathrm{H}_{\mathrm{C}}\right), \delta=3.168 \mathrm{ppm}\left(\mathrm{s}, 4 \mathrm{H}_{A}\right), \delta=4.639 \mathrm{ppm}\left(\mathrm{s}, 8 \mathrm{H}_{D}\right)$. 


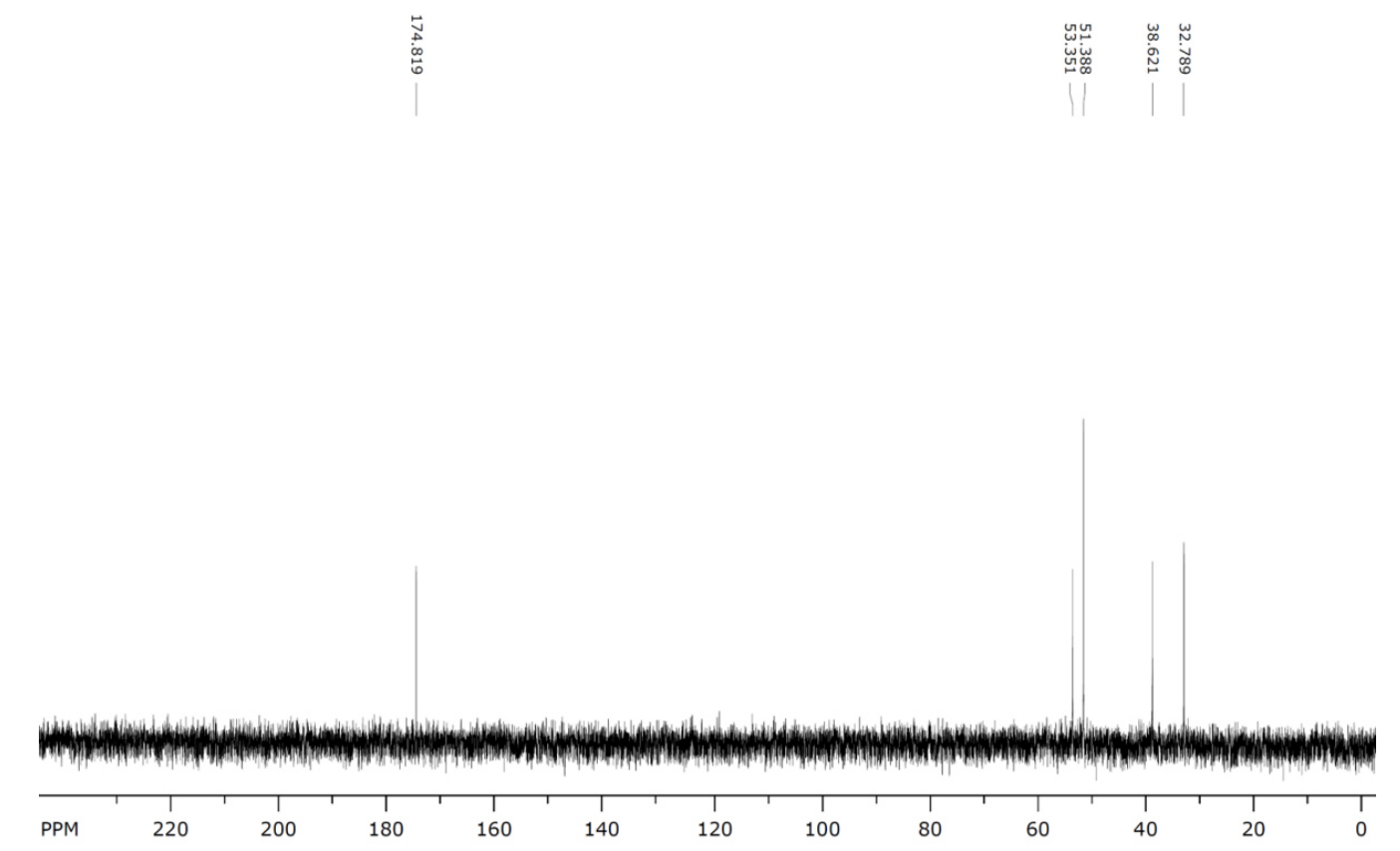

Figure $S 4:{ }^{13} \mathrm{C}-N M R$ spectrum of the PAMAM polymer in $D_{2} \mathrm{O} ; \delta=33 \mathrm{ppm}, 39 \mathrm{ppm}\left(C_{A}, C_{B}\right), \delta=51 \mathrm{ppm}$, $53 \mathrm{ppm}\left(C_{D}, C_{C}\right), \delta=175 \mathrm{ppm}$ (carbon atom of amide group). 


\section{IR spectroscopy of functionalized silica spheres}
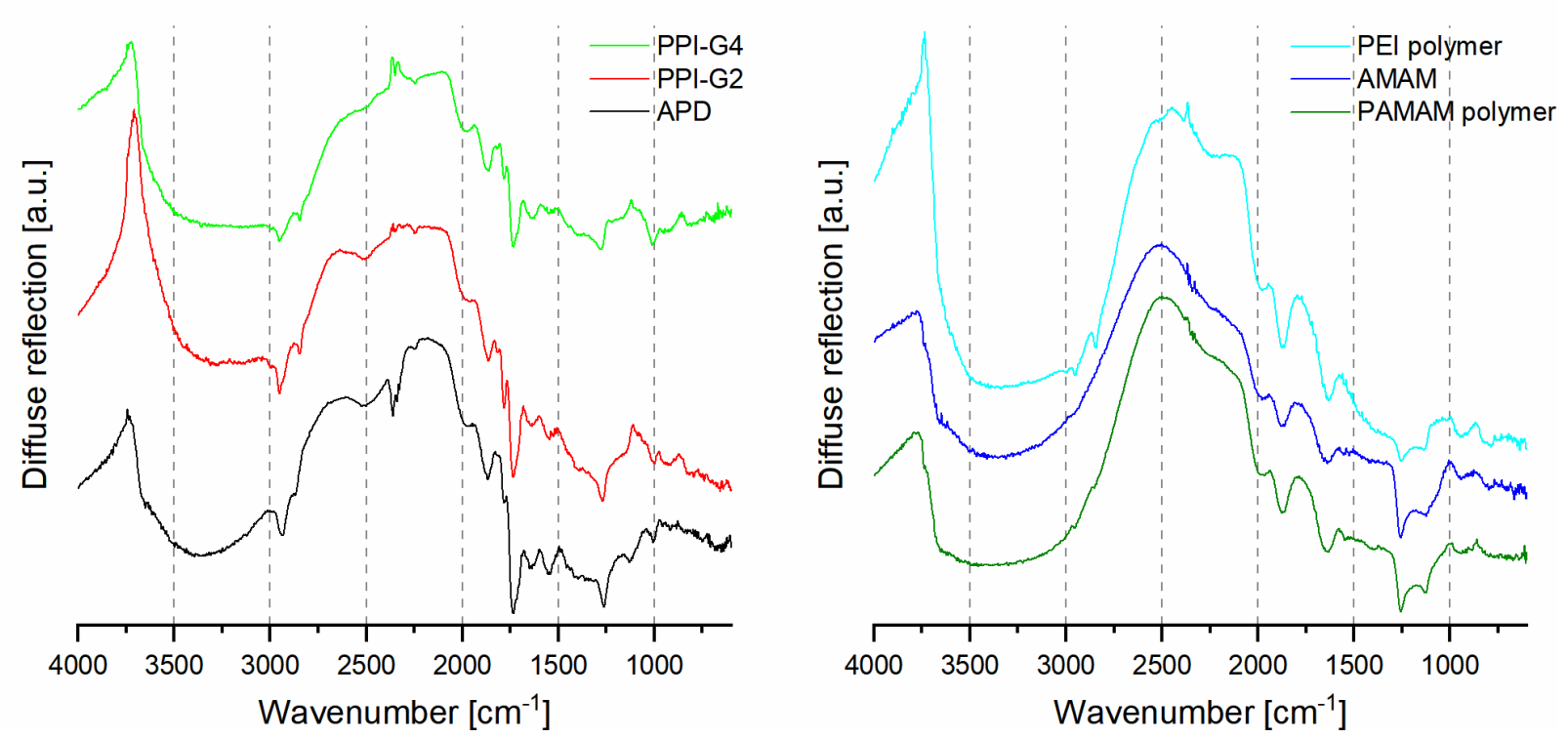

Figure S 5: DRIFT spectra of functionalized silica particles.

For all surface modifications, successful silanization can be proven by the negative band of the stretching vibration of the silanol groups at $3740 \mathrm{~cm}^{-1}$. The immobilization of the organic modifications is shown by the asymmetric and symmetric $\mathrm{C}-\mathrm{H}$-stretching vibration at $\sim 2940$ and $2840 \mathrm{~cm}^{-1}$. The band at $1730 \mathrm{~cm}^{-1}$ may be assigned to the $\mathrm{C}=\mathrm{O}$-stretching vibration of the carboxylic acid whereas the signal at $1640 \mathrm{~cm}^{-1}$ is caused by the amide I band $(\mathrm{C}=\mathrm{O}$-stretching vibration of secondary amide) as well as the $\mathrm{N}-\mathrm{H}$ deformation vibrations of primary amines. Both the $\mathrm{N}-\mathrm{H}$ deformation vibration of secondary amines as well as of the secondary amides (amide II band) contributes to the band at $1550 \mathrm{~cm}^{-1}$. Further assignment of vibrational bands is difficult, the signal at $1260 \mathrm{~cm}^{-1}$, however, may be caused by the amide III band as well as by the $\mathrm{Si}-\mathrm{CH}_{2}-\mathrm{R}$ vibration. C-C skeletal vibrations as well as $\mathrm{C}-\mathrm{N}$ stretching vibrations probably contribute to the band at $1130 \mathrm{~cm}^{-1}$, whereas Si-O-Si vibrations can be related to the signal at $1000 \mathrm{~cm}^{-1}$. 


\section{Further data of dynamic contact angle measurements}

Table S 3: Dynamic contact angles, obtained from tensiometric measurements with water and PBS buffer. Advancing and receding contact angles for the cycles 1, 2, 5 and 10 are given. For each surface modification, six wafers were analyzed $(n=6)$. Medians are provided (with $25 \%$ and $75 \%$ quartiles in brackets).

\begin{tabular}{|c|c|c|c|c|c|c|c|c|c|}
\hline & & \multicolumn{4}{|c|}{ Advancing contact angle } & \multicolumn{4}{|c|}{ Receding contact angle } \\
\hline & & $1^{\text {st }}$ cycle & $2^{\text {nd }}$ cycle & $5^{\text {th }}$ cycle & $10^{\text {th }}$ cycle & $1^{\text {st }}$ cycle & $2^{\text {nd }}$ cycle & $5^{\text {th }}$ cycle & $10^{\text {th }}$ cycle \\
\hline \multirow[t]{2}{*}{ Oxidized } & Water & $17(16-19)^{\circ}$ & $12(9-16)^{\circ}$ & $8(8-9)^{\circ}$ & $14(11-18)^{\circ}$ & $4(1-4)^{\circ}$ & $4(1-4)^{\circ}$ & $2(0-4)^{\circ}$ & $0(0-2)^{\circ}$ \\
\hline & PBS & $12(11-17)^{\circ}$ & $0(0-0)^{\circ}$ & $0(0-0)^{\circ}$ & $0(0-0)^{\circ}$ & $4(2-5)^{\circ}$ & $4(1-4)^{\circ}$ & $2(1-3)^{\circ}$ & $0(0-2)^{\circ}$ \\
\hline \multirow[t]{2}{*}{ APD } & Water & $58(57-60)^{\circ}$ & $45(41-49)^{\circ}$ & $44(43-44)^{\circ}$ & $44(43-44)^{\circ}$ & $8(7-10)^{\circ}$ & $9(8-9)^{\circ}$ & $8(7-9)^{\circ}$ & $8(7-10)^{\circ}$ \\
\hline & PBS & $59(57-61)^{\circ}$ & $33(31-35)^{\circ}$ & $32(32-33)^{\circ}$ & $31(31-32)^{\circ}$ & $7(6-8)^{\circ}$ & $8(8-8)^{\circ}$ & $9(9-9)^{\circ}$ & $9(8-10)^{\circ}$ \\
\hline \multirow[t]{2}{*}{ PPI-G2 } & Water & $60(59-63)^{\circ}$ & $59(57-63)^{\circ}$ & $66(57-70)^{\circ}$ & $70(62-77)^{\circ}$ & $3(2-3)^{\circ}$ & $4(3-6)^{\circ}$ & $6(5-6)^{\circ}$ & $6(5-9)^{\circ}$ \\
\hline & PBS & $58(53-63)^{\circ}$ & $48(44-53)^{\circ}$ & $47(42-52)^{\circ}$ & $47(43-51)^{\circ}$ & $7(5-9)^{\circ}$ & $6(4-9)^{\circ}$ & $6(4-8)^{\circ}$ & $6(3-8)^{\circ}$ \\
\hline \multirow[t]{2}{*}{ PPI-G4 } & Water & $65(64-67)^{\circ}$ & $62(57-63)^{\circ}$ & $72(67-79)^{\circ}$ & $80(73-85)^{\circ}$ & $2(0-4)^{\circ}$ & $1(0-3)^{\circ}$ & $3(1-5)^{\circ}$ & $4(1-5)^{\circ}$ \\
\hline & PBS & $61(60-62)^{\circ}$ & $54(47-56)^{\circ}$ & $53(49-56)^{\circ}$ & $54(52-57)^{\circ}$ & $7(6-8)^{\circ}$ & $7(6-7)^{\circ}$ & $6(6-7)^{\circ}$ & $6(6-7)^{\circ}$ \\
\hline \multirow{2}{*}{$\begin{array}{l}\text { PAMAM } \\
\text { polymer }\end{array}$} & Water & $36(35-37)^{\circ}$ & $36(33-41)^{\circ}$ & $42(40-46)^{\circ}$ & $49(44-56)^{\circ}$ & $4(4-5)^{\circ}$ & $4(3-5)^{\circ}$ & $4(3-4)^{\circ}$ & $3(1-4)^{\circ}$ \\
\hline & PBS & $32(31-33)^{\circ}$ & $30(29-33)^{\circ}$ & $30(29-33)^{\circ}$ & $30(29-32)^{\circ}$ & $11(9-12)^{\circ}$ & $10(9-12)^{\circ}$ & $11(9-12)^{\circ}$ & $11(9-12)^{\circ}$ \\
\hline \multirow{2}{*}{$\begin{array}{l}\text { PEI } \\
\text { polymer }\end{array}$} & Water & $57(57-58)^{\circ}$ & $64(60-70)^{\circ}$ & $71(66-74)^{\circ}$ & $73(67-77)^{\circ}$ & $6(5-6)^{\circ}$ & $7(6-10)^{\circ}$ & $8(6-12)^{\circ}$ & $8(6-14)^{\circ}$ \\
\hline & PBS & $53(52-58)^{\circ}$ & $46(45-46)^{\circ}$ & $46(45-47)^{\circ}$ & $47(46-48)^{\circ}$ & $8(7-9)^{\circ}$ & $8(7-9)^{\circ}$ & $8(7-9)^{\circ}$ & $8(7-9)^{\circ}$ \\
\hline \multirow[t]{2}{*}{ AMAM } & Water & $79(78-81)^{\circ}$ & $76(75-78)^{\circ}$ & $75(72-75)^{\circ}$ & $72(69-73)^{\circ}$ & $30(27-38)^{\circ}$ & $29(25-36)^{\circ}$ & $28(24-33)^{\circ}$ & $26(22-29)^{\circ}$ \\
\hline & PBS & $78(77-80)^{\circ}$ & $75(73-77)^{\circ}$ & $72(70-72)^{\circ}$ & $71(68-72)^{\circ}$ & $37(36-39)^{\circ}$ & $36(35-38)^{\circ}$ & $35(34-37)^{\circ}$ & $33(32-35)^{\circ}$ \\
\hline
\end{tabular}




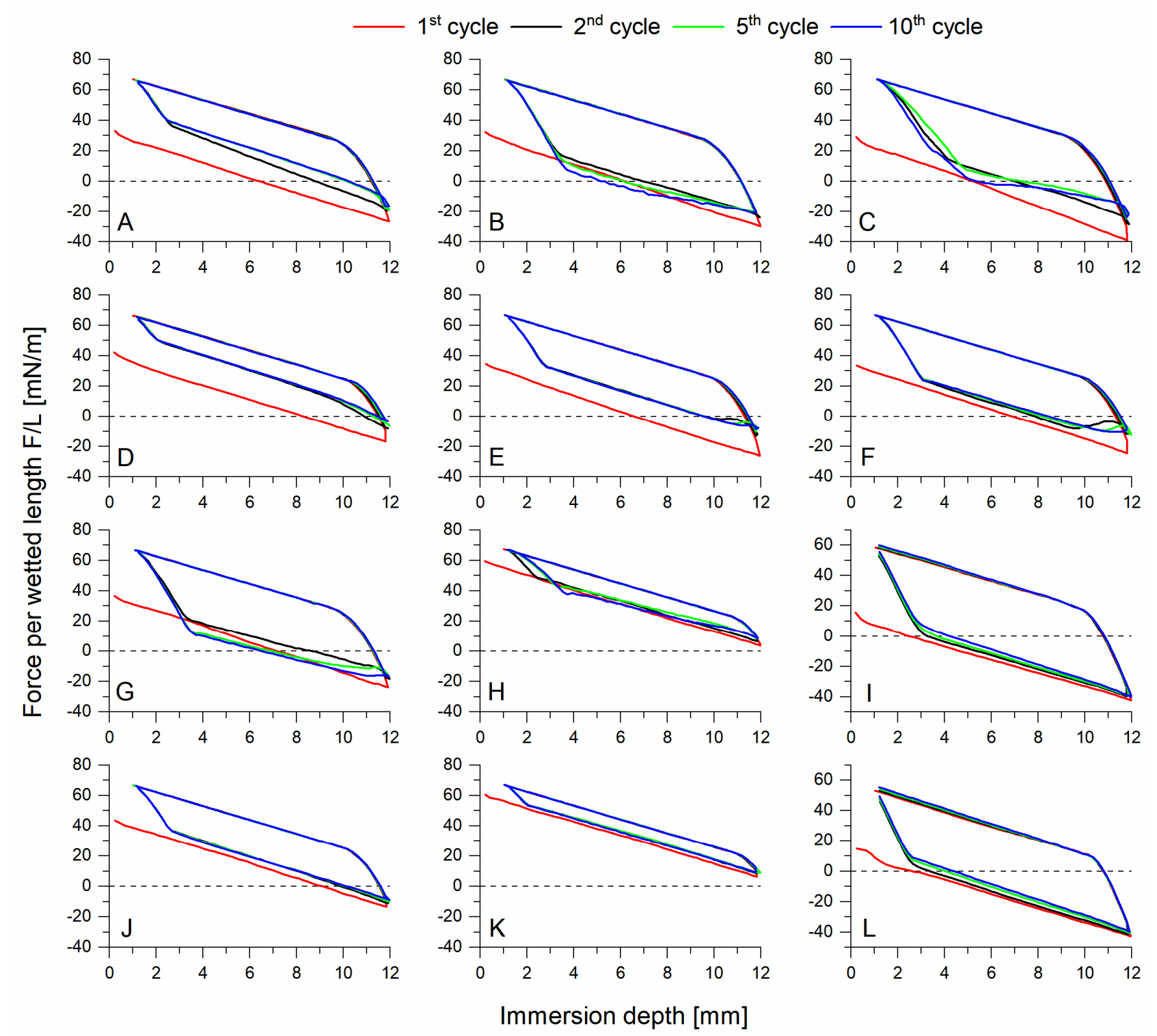

Figure S 6: Hysteresis cycles of dynamic contact angle measurements of functionalized Si wafers with water or PBS. Data from the $1^{\text {st }}, 2^{\text {nd }}, 5^{\text {th }}$ and $10^{\text {th }}$ immersion cycle is depicted. Note the differing $y$-axis in diagrams (I) and (L). (A) APD - water, (B) PPI-G2 - water, (C) PPI-G4 - water, (D) APD - PBS, (E) PPI-G2 - PBS, (F) PPI-G4 - PBS, (G) PEl polymer - water, (H) PAMAM polymer - water, (I) AMAM - water, (J) PEl polymer - PBS, (K) PAMAM polymer - PBS, (L) AMAM - PBS. 


\section{Dependence of protein adsorption on physicochemical surface properties}

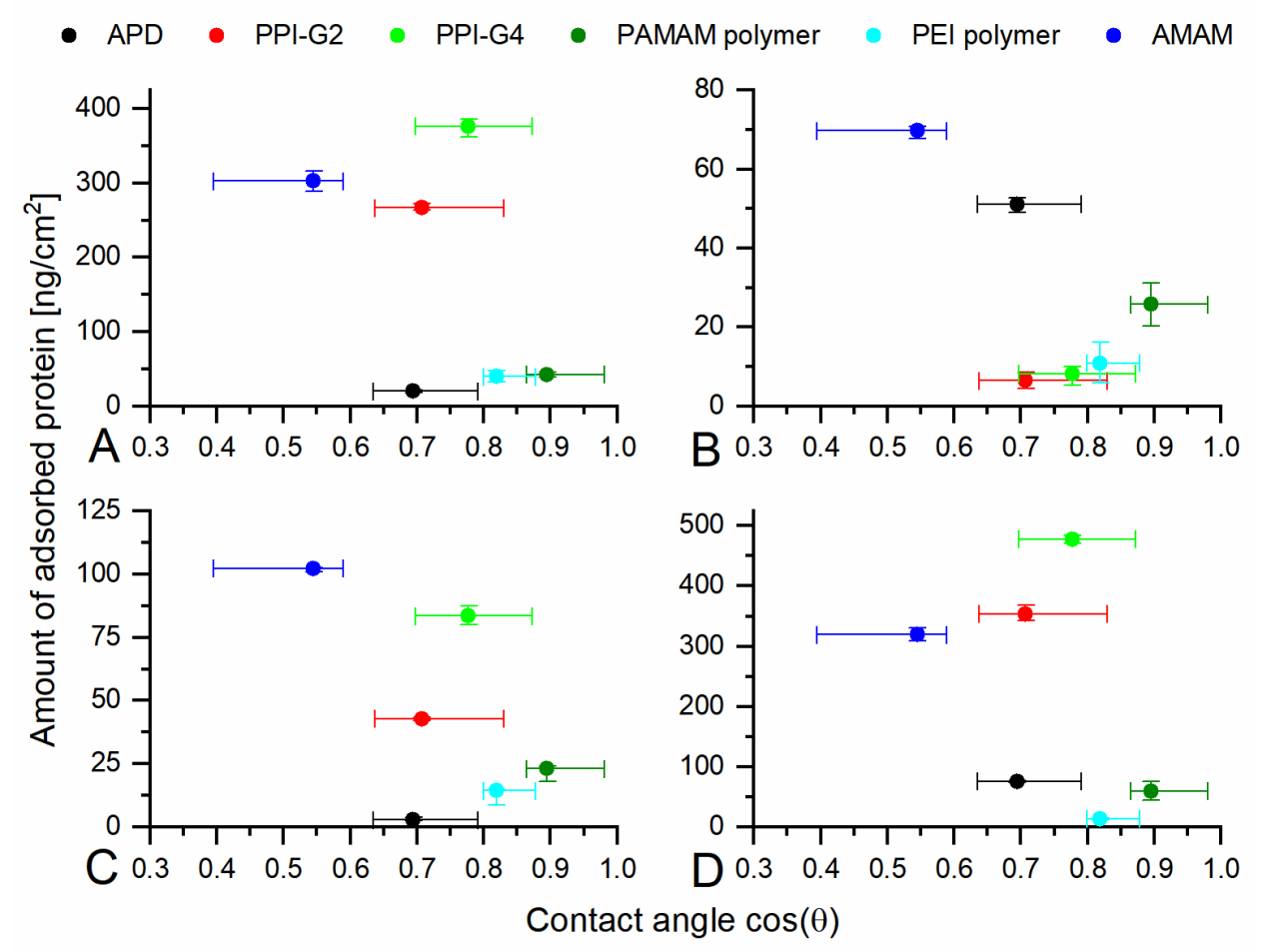

Figure S 7: Dependence of the protein adsorption from solutions of (A) HSA or (B) lysozyme as well as (C) saliva and (D) FBS on the wettability of the modifications, quantified via the static contact angle $\theta$. No correlation is visible. Medians are depicted (with interquartile range as error bars). 


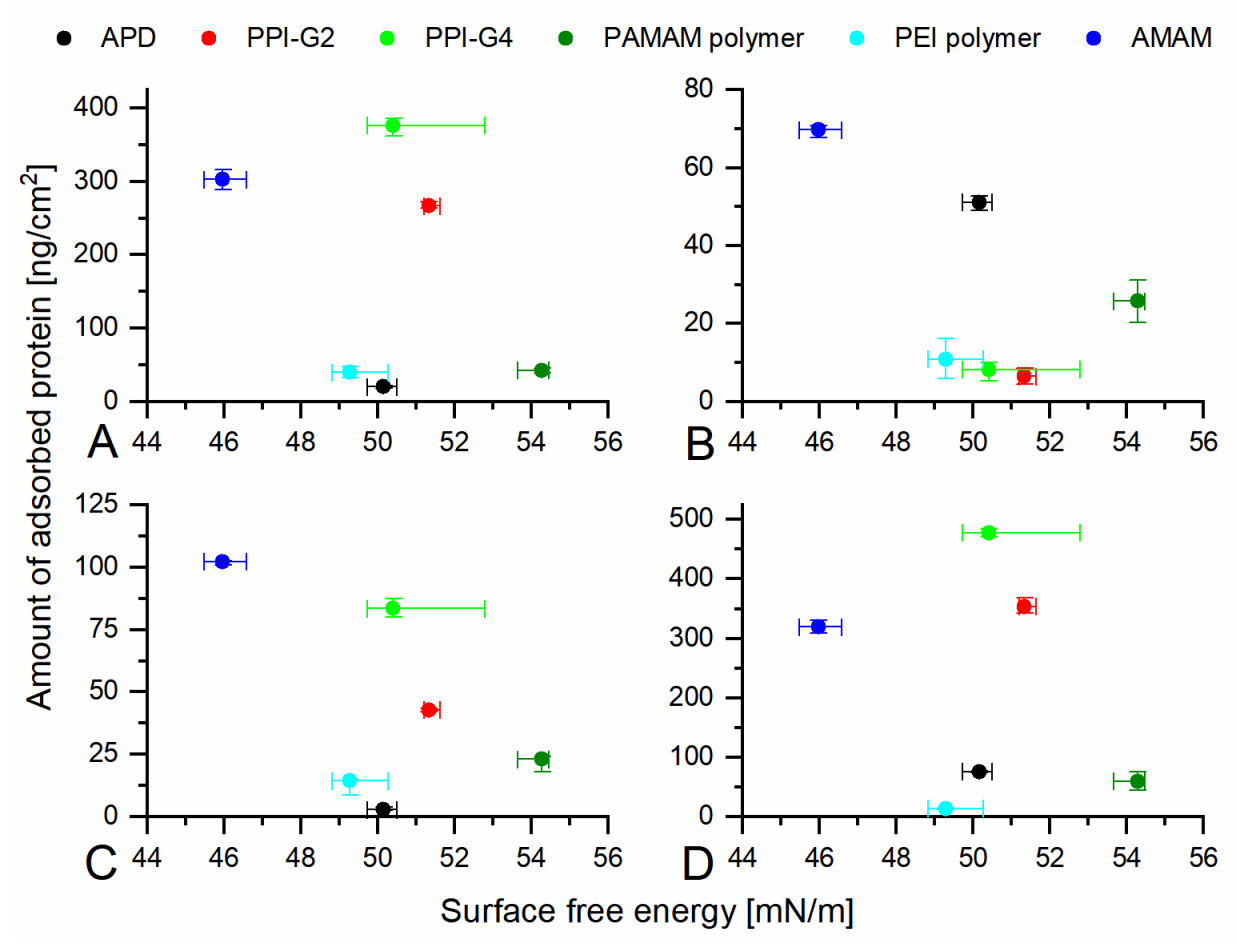

Figure S 8: Dependence of the amount of adsorbed protein on the SFE of the surface modifications. Adsorption from (A) HSA, (B) lysozyme, (C) saliva and (D) FBS. No correlation is visible. Medians are depicted (with interquartile range as error bars).

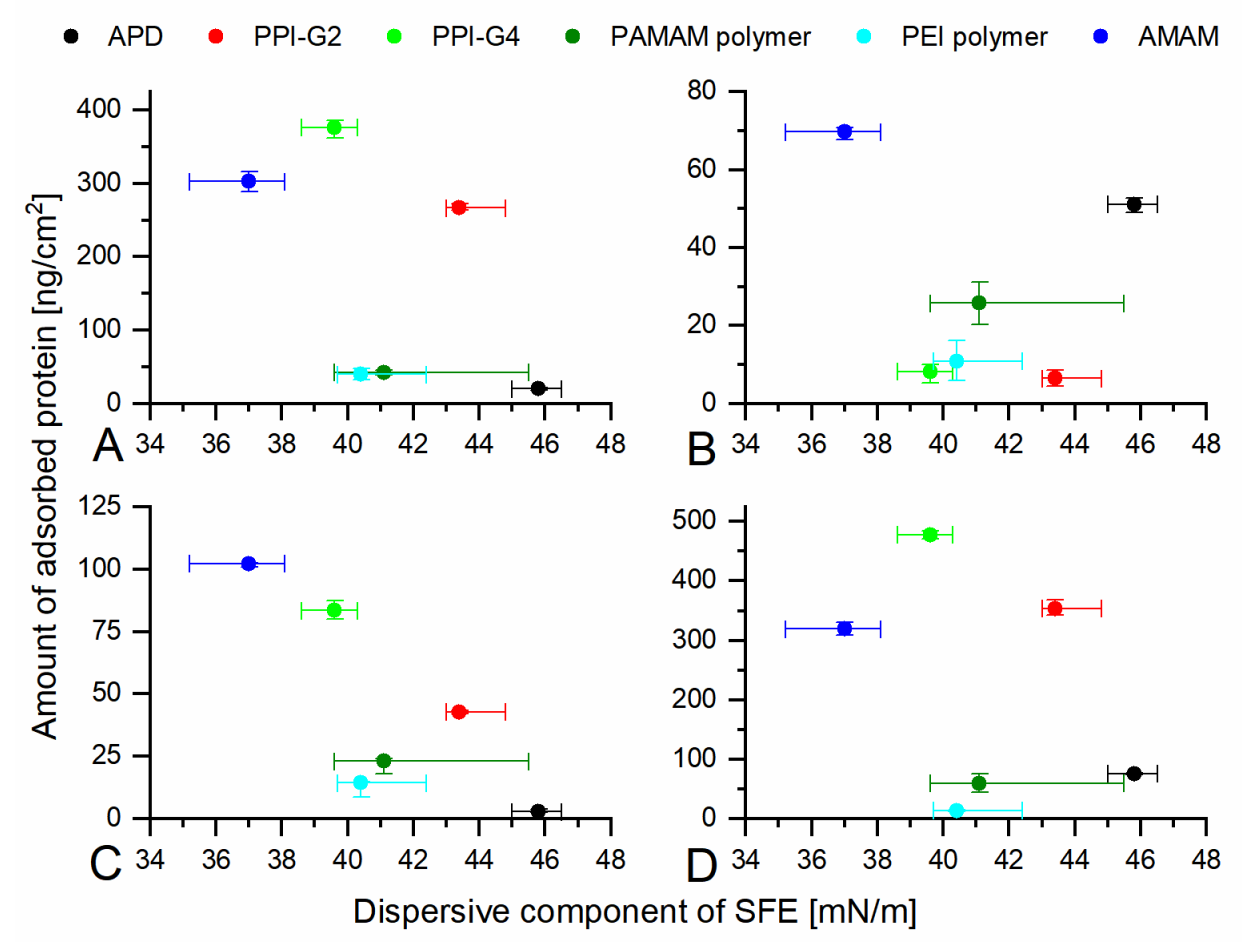

Figure S 9: Dependence of the amount of adsorbed protein on the dispersive component of the SFE. Adsorption from (A) HSA, (B) lysozyme, (C) saliva and (D) FBS. No correlation is visible. Medians are depicted (with interquartile range as error bars). 
- APD - PPI-G2 - PPI-G4 - PAMAM polymer • PEI polymer • AMAM
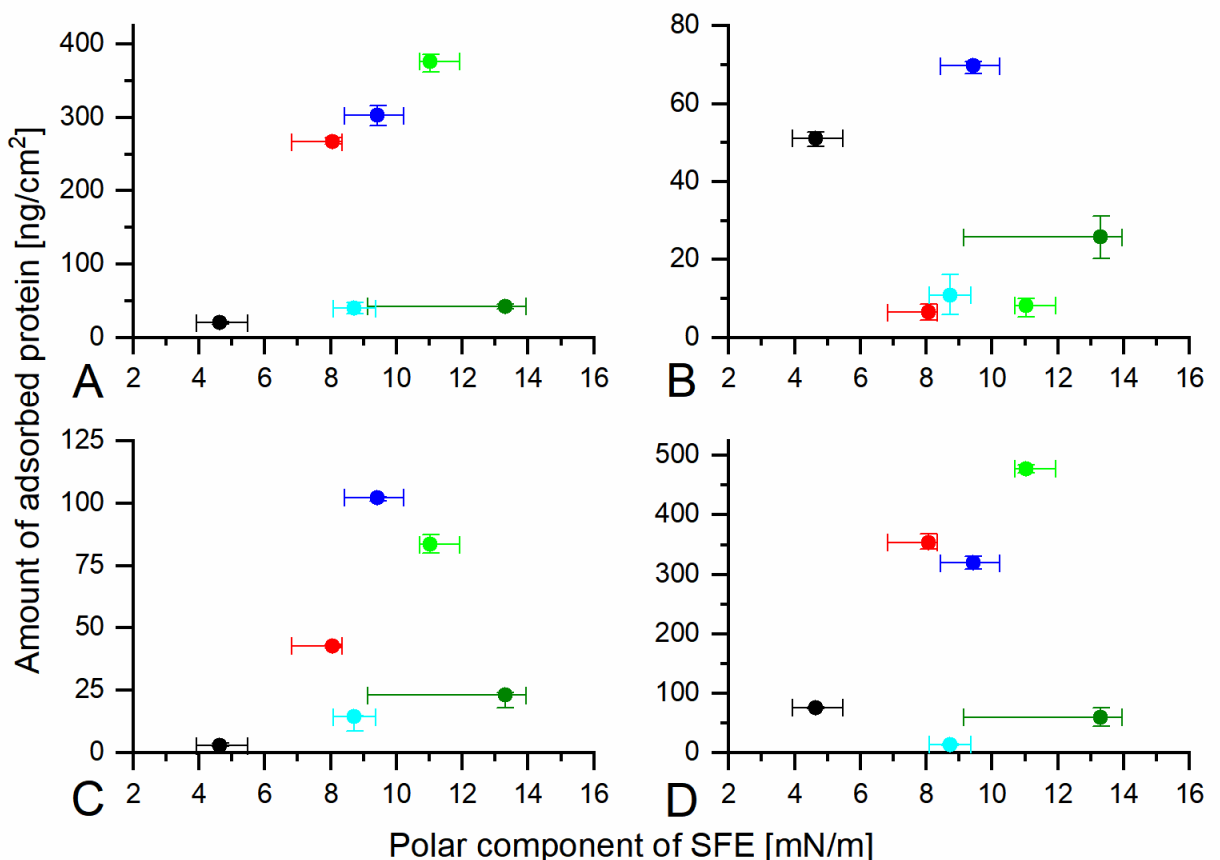

Figure S 10: Dependence of the amount of adsorbed protein on the polar component of the SFE. Adsorption from (A) HSA, (B) lysozyme, (C) saliva and (D) FBS. No correlation is visible. Medians are depicted (with interquartile range as error bars).

- $\mathrm{APD} \bullet \mathrm{PPI}-\mathrm{G} 2$ PPI-G4

- PAMAM polymer - PEl polymer

- AMAM
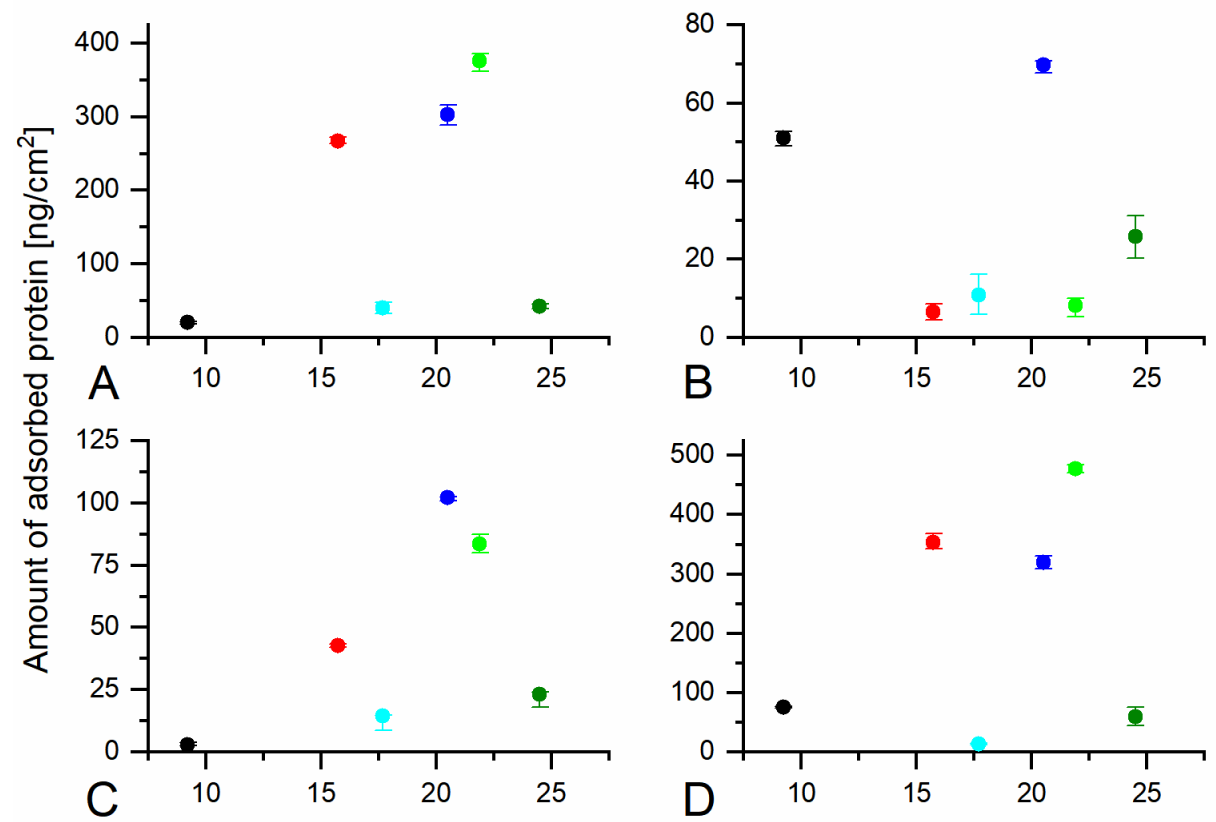

Polar component of SFE [\%]

Figure S 11: Dependence of the amount of adsorbed protein on the content of polar interactions of the SFE. Adsorption from (A) HSA, (B) lysozyme, (C) saliva and (D) FBS. No correlation is visible. Medians are depicted (with interquartile range as error bars). 


\section{References}

(1) Kwok, D. Y. The usefulness of the Lifshitz-van der Waals/acid-base approach for surface tension components and interfacial tensions. Colloids and Surfaces A: Physicochemical and Engineering Aspects 1999, 156, 191-200.

(2) Socrates G. Infrared and Raman characteristic group frequencies: Tables and charts, 3rd ed.; Wiley: Chichester, 2001. 